\title{
La prisión de los conceptos: escoria, exclusión social, interacción y agencia
}

\section{Joan Uribe Vilarrodona}

Universidad de Barcelona y Consorci de Serveis Socials de Barcelona

joan.uribe@ub.edu

\begin{abstract}
Historikoki, gizarte-baztertuen etiketa eransten zaien pertsonak ikuspegi moralizatzaileetatik kudeatu beharreko ustezko gizarte-arazo bat bezala hartuak izan dira. Logika hori XX. mendearen erdialdera arte mantendu da, justizia sozialaren eta giza eskubideen nozioa zabaltzen hasi zen arte, hain zuzen. Hala ere, gizarte-zerbitzuen sistema modernoak oraindik indarrean dagoen eredu historikotik abiatuta aktibatu dira, Zuzenbide Estatuaren beste sistema batzuek pertsona jakin batzuk artatu gabe utzi izan dituztela -edota, sarritan, sentimenduaren logikatik artatu izan dituztela - onartuta. Gaur egun, argi dago gizartezerbitzuen eginkizun espezifikoak eta nagusiak -haien eskuduntza alorreko mandatuak- pertsonen interakzioa berreskuratzeko eta mantentzeko laguntza espezializatua eskaintzea izan behar duela, hori delako gizarte-inklusioa -eta, beraz, gizartejustizia, gizarte-kohesioa eta ekitatea- lortzeko gako nagusia.
\end{abstract}

\section{GAKO-HITZAK:}

Gizarte-bazterketa, estigma, interakzioa, gizartezerbitzuak, Zuzenbide-Estatua.
Históricamente, las personas que reciben la etiqueta de excluidas sociales han sido tratadas como un presunto problema social a gestionar desde perspectivas moralizantes. Esta lógica se ha mantenido hasta mediados del siglo $\mathrm{XX}$, cuando comienza a incorporarse la noción de justicia social y el derecho de las personas. No obstante, los sistemas de servicios sociales modernos se han activado a partir del aún vigente modelo histórico, asumiendo la incapacidad de otros sistemas del Estado de Derecho para atender a determinadas personas en el ámbito de sus competencias, y hacerlo con frecuencia desde la lógica del sentimiento. Hoy, parece claro que la misión específica y central de los servicios sociales, su encargo competencial, debe ser el acompañamiento especializado para la recuperación y mantenimiento de la interacción de las personas, eje central de la inclusión social y, por tanto, de la justicia social, la cohesión social y la equidad.

\section{Palabras Clave:}

Exclusión social, estigma, interacción, servicios sociales, Estado de Derecho. 


\section{Introducción}

A lo largo de la historia, las personas que reciben hoy la etiqueta de excluidas sociales han sido tratadas como un presunto problema social a gestionar desde perspectivas moralizantes. Esta lógica se ha mantenido durante siglos, hasta que a mediados del siglo XX se incorpora mediante el Estado de Derecho la noción de justicia social y el derecho de las personas, sustituyendo progresivamente la lógica anterior a nivel de discurso y relato. No obstante, los sistemas de servicios sociales modernos se han activado a partir del aún vigente modelo histórico, asumiendo a su vez la incapacidad de abordaje de los problemas de determinadas personas por parte de otros sistemas del Estado de Derecho en el ámbito de sus competencias, y hacerlo con frecuencia desde la lógica del sentimiento. La combinación de estos tres factores define el erróneo enfoque actual de los servicios sociales. Hoy parece claro que la misión específica y central de los servicios sociales, su encargo competencial, debe ser el del acompañamiento especializado para la recuperación y mantenimiento de la interacción de las personas, eje central de la inclusión social y, por tanto, de la justicia social, la cohesión social y la equidad. Este debería ser el enfoque primario a partir del cual reconstruir desde sus cimientos los sistemas de servicios sociales.

\section{Escoria}

La tea requemada por el paso de los siglos a la que actualmente llamamos "exclusión social” ha recibido antes otros nombres que explican las distintas miradas sobre este material social cuyos individuos, durante siglos, han ardido operando como fuegos fatuos.

A partir de una perspectiva histórica tomada desde los siglos X-XI, puede entenderse que es desde ayer mismo que la aceptación y desarrollo del imperfecto concepto de exclusión social nos ha ido alejando progresivamente de lo que, en el fondo, siempre se entendió que este encarnaba: la “escoria”. Esa sustancia formada de impurezas, residuo inútil del crisol, característica orgánica que ha sido adjudicada durante siglos a unos cuantos: la escoria social. Conformada por seres socialmente impuros, una tara en relación con lo que se supone que debe ser y hacer una persona en su contexto social. Por esa tara, más social y moral que física, las personas en ella encasilladas han sido tratadas como supuestamente inútiles, cuando no excedentes.

Se ha callado siempre - secreto a voces- la importante función simbólica y económica que, de manera eficiente y ordenada en el seno de toda organización social, han desarrollado quienes han sido arrojados a esa miserable condición estigmatizante (Woolf, 1989). ¿Inútiles? De ninguna manera. ¿Desviados? Para el discurso predominante, sí. En tanto que escoria, se les ha ubicado socialmente como anormalidad, como una materialización humana que no debería haber ocurrido. Y así se les ha controlado, gestionado y tolerado en línea a su mayor o menor disponibilidad a comprometerse - de forma voluntaria o no- a abandonar su condición de estorbo presuntamente inútil y defectuoso bajo promesa, requerimiento o amenaza, para así acercarse en lo posible a la supuesta normalidad de una mayoría aceptada y aceptable.

Hay múltiples normas que evidencian desde la Edad Media este enfoque en el que hasta los siglos XIII a XIV el "pobre" ocupaba un espacio necesario para la materialización social de la moral cristiana. El pobre evangélico cumplía una función simbólica con relación al valor cristiano de la caridad y su función salvífica, pero también engranaba a un sistema económico que necesitaba a esta concreta franja social, su cuota y su valor, tanto productivo como en tanto que consumidores pobres que, a veces, no podían ser contenidos por la caridad cristiana, liberando su malestar de tanto en tanto a través de revueltas, violentos alborotos, o pogromos contra chivos expiatorios.

Así fue como aparecieron instituciones como las pias almoinas, presentes en diversas ciudades como la documentada desde 1009 en Barcelona, que proveyó de sustento durante siglos tanto a los pobres de solemnidad -aquellos que no tenían literalmente donde caer muertos-, como a los pobres vergonzantes - aquellos radicalmente venidos a menos en su condición social-, grupos que eran repudiados por igual por el resto de sus coetáneos. También en este momento vieron la luz los primeros hospitales, dependencias en las que atender a los enfermos y a los pobres ambulantes, a los huérfanos y a los enfermos: en general, a los hospites -los huéspedes, los visitantes, los extranjeros-, en centros primero pequeños e ineficientes que con el paso de los siglos serán mayores e incorporarán progresivamente su esfuerzo y atención en la provisión de servicios orientados a la salud (Vilà, 2004).

A consecuencia de sucesivas guerras y epidemias, el paso de los siglos conllevó la masificación de la pobreza, que a partir del siglo XIV condujo a una revisión del abordaje de esta "escoria” que, de manera progresiva, transitó de la encarnación del pobre evangélico a partir del cual practicar la caridad cristiana, a ser visto y gestionado como un mero peligro social a través de la doble categorización de pobre verdadero y pobre falso o fingido. Los hospitales comenzaron a incorporar este criterio de clasificación, como también lo hicieron poco después las casas de misericordia, decidiéndose en cada caso, lugar y momento a lo largo de los siglos, aquellos criterios que separaban al pobre bueno del pobre malo, siempre con un hilo conductor en común: buen pobre - o pobre verdadero- sería aquel que se sometiese en obediencia para hacer lo que se le ordene. Y mal pobre - o pobre falso-, el 
que decidiera por sí mismo sobre su vida y condición: a este, represión, punición, exilio, expulsión. Se crearon incluso en algunas villas y ciudades equipos de selección que, una vez evaluado cada caso, facilitaban una identificación visual a los pobres verdaderos para que los cristianos pudiesen ejercer con ellos la caridad cristiana y a su vez ayudar en la persecución y castigo de los no acreditados como tales, los pobres falsos (Vilà, 2004).

Así, y en relación con este doble rasero instituido desde la norma legal, Benjamín Pamplona aporta ejemplos como la ordenanza del rey Pedro de Castilla de 1351 que instituía la pena de látigo para los mendigos sanos. 0 la ley del rey don Juan que, en 1387 en Briviesca, ordena que: “los vagabundos serán echados y castigados, los legítimos pobres que sean curados en los obispados donde son naturales y si siendo bastante proveídos tornaren a mendigar, sean castigados" (Pamplona O.H., 1982: 2). En este contexto, el dominico Domingo de Soto (1545), que fue otro pionero y defensor de los pobres, acusador de los abusos de los poderosos, definió claramente el doble abordaje en base a "pobres verdaderos, que han de ser remediados" y "pobres fingidos, que han de ser punidos” (Pamplona O.H.: 1982, 2).

En relación con las casas de misericordia, donde serían recogidos los mendigos, fue en 1578 cuando el canónigo de Elna, Miguel Giginta, sometió a las Cortes de Madrid un proyecto de fundación de estas en las principales ciudades. Giginta, que en su Tratado de remedio a los pobres hizo un alegato en defensa de estos y una crítica a los poderes públicos, ejerciendo influencia en los trabajos posteriores de Luis Vives (Vilà, 2004), se mantuvo en cualquier caso siempre dentro de la línea de abordaje de la pobreza a partir de la discriminación entre buenos y malos pobres, pues sostenía que: “[...] así se podrá separa a los verdaderos pobres de los simuladores viciosos, que, sobre todo, dan mal ejemplo [...]; los pobres auténticos recibirán todo lo que necesiten; llevarán una vida cristiana; no importunarán al público en la calle e iglesias; los pobres fingidos no desviarán de su fin las limosnas que se dedicarán a los pobres vergonzantes, que de este modo estarán mejor atendidos” (Pamplona O.H., 1982).

No olvidemos que quienes a lo largo de la historia recibieron el tratamiento al que nos estamos refiriendo, fueron las personas cuyas situaciones vitales discurrían en una cotidianidad al margen de los circuitos normalizados de relación con la producción de riqueza y de su consumo, y que, a su vez, precisamente por ello o como su consecuencia, eran repudiadas por sus respectivas sociedades en tanto que no eran "de los nuestros". Era responsabilidad de cada cual estar a la altura de la norma social, formal o informal. Para ellos y ellas, diferentes enfoques a lo largo de los siglos como los de Luis Vives, la Reforma de Lutero, la Contrareforma o el Concilio de Trento, acompañaron con mejor o peor tino una orientación que, centrada en la lógica del control sobre la escoria social asentada en los siglos precedentes, avanzó hacia una intención de "reeducación" y aprovechamiento de esta escoria, vinculada a un programa de reforma moral y religiosa (Vilà, 2004), hasta llegar a las lógicas mercantilistas de los siglos XVII y XVIII sobre la utilidad de la pobreza (Lis-Hugo, 1982).

Llevemos ahora esta revisión hasta el siglo XIX, con Charles Dickens, que ilustró a través de muchas de sus obras esta parte de la sociedad entendida como escoria en el sentir colectivo. Explorador impenitente de la vida y de las calles del Londres de su tiempo, lo recogió en sus obras sin medias tintas, mostrándonos dos de sus caras: la ostentosa e imperial, y la sumida en la miseria que él mismo sufrió cuando niño a causa del encarcelamiento por deudas de su padre en la tristemente famosa cárcel de Marshalsea, motivo por el que el Dickens niño se mantuvo, solo, trabajando en una fábrica y ayudando a liquidar la deuda paterna. Así fue como formó parte de esa legión de escoria en tanto que víctima de la explotación infantil en una fábrica londinense del siglo XIX, viviendo situaciones que sin duda le inspirarían en obras como Oliver Twist, en las que desgrana - y descarna- esa vida. 0 en el perfil desolador, casi terrorífico de los personajes Ignorancia y Necesidad, dos niños de condición miserable que se le aparecen a Ebenezer Scrooge en Cuento de Navidad. También son de esa misma época los testimonios gráficos que sobre esa marisma social compuesta por la escoria del Londres victoriano aparecen recogidos por la revista satírica Punch, así como por ilustradores ingleses a los que con frecuencia parecía moverles más el interés moralizante que el puramente descriptivo o de denuncia: porque la escoria, escoria es, y debe ser rescatada - no tanto sus cuerpos como sus almasde su condición.

En la segunda mitad del siglo XIX, en algunos de los poemas de los Cuadros Parisinos de la colección publicada como Las flores del mal, Baudelaire nos toma de la mano y nos invita a abrazar e integrar sin más a esa escoria con nombre propio. Con cuerpo. Con alma. A sentir su tacto, su olor. A incomodarnos desde el respeto ante esos seres con necesidades, dolor, luchas, contradicciones y carencias que sobrepasan al lector. A entender - sin moralismosque sin ellos y ellas la sociedad de Baudelaire sencillamente no sería y que constituyen, por tanto, parte irrenunciable de la modernidad.

Vayamos a otro ejemplo de la condición proscrita de aquellos que han sufrido la pobreza extrema entendida como escoria social, visión que parece haberse confirmado inexorablemente a lo largo de la historia, también el reconocimiento de Engels hacia Robert Owen en las numerosas alusiones que sobre él hace Engels en Del socialismo utópico al socialismo científico (Engels, 2008). No obstante, y como es sabido, la propuesta capital de Owen fue la de las home colonies, las sociedades modelo en las que se definía como objetivo "recuperar" a la escoria, como bien explica en su libro Nueva visión 
del mundo, de 1813, el primero de su colección sobre "la formación del carácter" en términos puramente moralizantes, como se deduce de lo que Owen dice en esta obra:

Se permite actualmente que el carácter de estas personas se forme sin una guía o dirección adecuada y, en muchos casos, bajo circunstancias que directamente les obligan a un camino de extremo vicio y miseria; volviéndolos así los peores súbditos y los más peligrosos del imperio; mientras que la mayor parte del resto de la comunidad se educa con la mayoría de principios errados de la naturaleza humana, lo que sin duda, produce una conducta general, a través de la sociedad, totalmente indigna del carácter de los seres racionales. (Owen, 2007: 37)

Una vez más, se evidencia la imperativa y prioritaria necesidad de redención moral de los sujetos que han sufrido las carencias absolutas vinculadas a la pobreza extrema. Necesidad que, de hecho, parece haber estado presente como objetivo principal en todo enfoque y mirada.

Una última revisión histórica sobre el trato y encaje que recibía la escoria ya en el siglo XX la tomaremos de la mirada que propone George Orwell en su libro Vagabundo en París y Londres, publicado en 1933 y escrito presuntamente a partir de una mezcla de experiencia personal motivada por la vocación documental y la literaria. En cualquier caso, esta obra recoge, en su parte relativa a Londres, una verosímil descripción, episódica y reiterativa, de formas de tratamiento de la pobreza y privación extrema en el primer tercio del siglo XX a partir del abordaje en el que se sumaba el control casi carcelario de las personas sin hogar, con un apoyo caritativo y asistencialista en espacios a medio camino entre la cárcel del siglo XIX y el modelo de dispositivo social de primera acogida vigente aún en la segunda mitad del siglo XX y principios del XXI.

En sus páginas encontramos descripciones como la siguiente: "Por lo que decían, daba la impresión de que todas las manganeras ${ }^{1}$ son diferentes, cada una con sus peculiares méritos y deméritos, y es importante conocerlos cuando estás en la calle. Un veterano te explicará las peculiaridades de cada manganera inglesa así: en A se permite fumar, pero hay chinches en las celdas; en $B$ las camas son cómodas, pero el conserje es un capullo; en $C$ te dejan salir temprano, pero el té es imbebible; en $D$ los encargados te roban el dinero si llevas algo... y así sucesivamente sin interrupción" (Orwell, 2010: 209). Otras como: "Con sus filas de ventanucos enrejados y los altos muros y portones de hierro que la separaban del camino, tenía bastante aspecto de prisión. Ya había una larga cola de harapientos esperando a que se abrieran las puertas" (Orwell,

${ }^{1}$ Manganera u hospicio son las dos formas con las que Orwell se refiere a lo que hoy llamaríamos albergue, centro de primera acogida o centro de baja exigencia, por citar algunas fórmulas actuales.
2010: 208). 0: "La manganera de Edbury no se diferenciaba mucho de la de Romton. Lo peor era que se confiscaba todo el tabaco a la entrada, y nos advirtieron de que, si cogían a alguien fumando, le echarían de inmediato. Según la Ley de Vagabundos, los transeúntes podían ser procesados por fumar en la manganera; de hecho, podían ser procesados casi por cualquier cosa. Pero las autoridades se ahorraban las molestias de una demanda echando a los desobedientes a la calle" (Orwell, 2010: 223-224).

Lo que Orwell nos relata es, una vez más, el abordaje clásico a lo largo de los siglos de esa presunta bajeza moral atribuida a las clases sociales más privadas de derechos y recursos. Un abordaje que se explica de nuevo desde un moralismo que presupone a cada individuo como único y consciente propietario de su propio destino y que Virginia Woolf retrata a principios del siglo XX en Fin de viaje, en una conversación entre Rachel Vinrace y Richard Dalloway:

-Veamos. Debajo del nivel de la calle palpita la vida. ¿No es así? En los hilos eléctricos, conducciones de agua, teléfono, en los hombres que limpian las cloacas y en los que conducen carros de basura. ¿No siente usted palpitar esa vida cuando abre un grifo y mana de él un chorro de agua?

-Evidentemente -dijo Richard, que había escuchado con interés-. Las bases de la sociedad moderna se asientan en la cooperación de muchas voluntades. Si fueran muchas las personas que supieran entenderlo así, habría menos pobres de verdad, o sea, pobres morales. (Woolf, 1976: 71)

Centrémonos ahora en el periodo entre el antes y el después de la Segunda Guerra Mundial cuando, a partir de las incipientes propuestas de los diferentes modelos de Estado Social, el político liberal británico William Henry Beveridge se entregó a la reflexión y diseño de lo que serían las bases teóricas del Estado del Bienestar que ayudarían a desarrollar el Estado Social de Derecho a partir de 1946. Sus informes sentaron las bases de lo que se desarrollaría en distintos países de diferentes maneras en forma de sistemas de seguridad social a partir de un sistema de contribución y redistribución -y no de un sistema asistencialista-. El punto de partida de Beveridge se situaba en la necesidad de abordar "[...] los cinco gigantes que hay que destruir - la indigencia, las enfermedades, la ignorancia, la suciedad y la ociosidad-" (Beveridge, 1987: 51).

Beveridge identificaba ocho causas primarias de la necesidad: "el desempleo; la incapacidad laboral; la pérdida de los medios de vida por una persona que no depende de un trabajo remunerado; el retiro del trabajo; necesidades matrimoniales de una mujer atendidas por una política de ama de casa que incluye provisión frente a ciertas situaciones de necesidad; los gastos de defunción; infancia y enfermedad o incapacidad física" (Monereo, 2015: 
289). La aportación de Beveridge sentó las bases para que, a través de un sistema de seguridad social como uno de los pilares del Estado de Derecho, se trascendiese y superase progresivamente a los sistemas -y al pensamiento- basados en la graciable caridad. Beveridge se enfocó en satisfacer desde el derecho las necesidades del conjunto de la sociedad, rompiendo - en la teoría- con la concepción clásica de una escoria social como clase constituida.

Tras la Segunda Guerra Mundial ya nada sería igual. La humanidad había vuelto a empeñar su sangre en la destrucción del planeta, de su historia y de sus culturas. El renacimiento tras la gran destrucción masiva ofrecía grandes oportunidades y precisaba de grandes discursos sobre lo humana que debía llegar a ser la humanidad. Una mano -teórica- se tendería -teóricamente- en apoyo de la escoria social. Y, siguiendo ese rastro, Europa asentaría con fuerza en los años sesenta un proyecto y un relato diferencial respecto al resto del planeta: el del Estado del Bienestar. Europa: de motor de destrucción planetaria, a feudo y faro de la humanización y de los derechos, aunque fuese tan solo a efectos de relato. Así fue como la segunda mitad del siglo XX vio nacer el concepto de exclusión social para renombrar a los que, no obstante, seguirían siendo vivenciados como la escoria marginal que no habían dejado de ser durante siglos.

\section{Exclusión social}

En cualquier caso, el desarrollo de los distintos modelos de seguridad social implicó un nuevo contexto y, con él, nuevos abordajes. La sociedad se diseñaba desde el beneficio de sistemas de coberturas garantizadas por derecho que proveerían necesidades no cubiertas hasta entonces. Podría suponerse que este enfoque incluiría a la totalidad de miembros de una sociedad. Pero no fue así. Lo constató, entre otros, uno de los análisis de esta realidad realizado por Lenoir en 1974 en su libro Les Exclus, un Français sur dix, y en el que acuñó el concepto de "exclusión social".

Lenoir utilizó el término "excluido" con relación a quienes, según él, no eran capaces de beneficiarse de los frutos del crecimiento económico (Martínez Veiga, 2008), al considerar que en el nuevo sistema de seguridad social una parte de la población, la formada por "minusválidos físicos y psíquicos, personas con tendencia al suicidio, ancianos inválidos, niños de los que se ha abusado, consumidores de droga, delincuentes, hogares monoparentales, unidades domésticas multiproblemáticas, marginales, personas asociales y otros inadaptados sociales [...] no estaban protegidas por ningún tipo de sistema de seguridad social” (Martínez Veiga, 2008: 8).

No obstante, ¿es porque quedan fuera de cobertura por razones internas de la propia gestión del sistema de seguridad social que Lenoir los identifica como supuesto grupo, o lo que hace es identificar al grupo que a mediados del siglo XX hereda la histórica clasificación social de escoria, y que de cualquier manera no estaba previsto que llegase a formar parte del sistema de juego? ¿Cuáles serán las repercusiones de la confusión entre situación social precaria y condición económica insuficiente, como si fuesen sinónimos, con relación a la activación de recursos para la cobertura de déficits sociales? Retomaremos estas preguntas más adelante, puesto que son cruciales para analizar el posible juego de ocultación del tratamiento histórico y la terrible confusión generada al crear los actuales sistemas y mecanismos de respuesta y atención a la "exclusión".

Según Martínez Veiga, el concepto de exclusión social evolucionó cuando, en relación con el Ingreso Mínimo de Inserción instaurado en 1988 en Francia, se catalizaron dos interpretaciones de la exclusión: una, la que recogería a los que quedan al margen de una supuesta gran clase media y minoritaria clase alta, y que serían parados de larga duración y personas con minusvalías físicas, psíquicas y sociales. Y otra interpretación, complementaria a la primera, que, siguiendo a Robert Castel, entendería la exclusión social como "un conjunto de relaciones sociales con la sociedad como un todo" (Castel, 1997, cit. en Martínez Veiga, 2008: 11-12). Castel, nos dice Martínez Veiga, sitúa la exclusión en el contexto de dos vectores: uno, el que se deriva de la sociedad salarial, y el otro, a partir del "aflojamiento" de relaciones - con la comunidad, sociedad, familia, amigos-, que pueden llevar a la persona a la ruptura y aislamiento social. El cruce de los vectores genera, según Castel, vulnerabilidades que pueden conllevar lo que al autor nombra como "desafiliación" - la ruptura del lazo social-.

A partir de estas lógicas definidas desde la segunda mitad del siglo XX, los servicios sociales actuales se han dotado de contenido a partir de un confuso híbrido, compuesto por una continuidad del modelo histórico ya presentado de gestión de la escoria social y desde sistemas, servicios y dispositivos parecidos en muchos casos a los de hace siglos, más una vertebración de derechos sustentados en los modelos de Estado de Bienestar, pero pensados no para la sociedad, sino para la escoria, que ha seguido siendo gestionada como tal. La intención, no obstante, ha sido y es buena. Y quizá por ese motivo, como dice Martínez Veiga citando a Boltanski y Chiapello:

[...] el modelo de exclusión permite designar una negatividad sin pasar por la acusación. Los excluidos no son víctimas de nadie, a pesar de que su pertenencia a una comunidad humana (o a una ciudadanía común) exige que sus sufrimientos sean tomados en cuenta y sean socorridos especialmente por el Estado [...]. El tema de la exclusión, brota por ello, de lo que hemos denominado un "campo del sentimiento" 
en oposición a un "campo de la denuncia" [...] lo cual favorecerá que diez años más tarde sea reapropiada por el movimiento humanitario. (Martínez Veiga, 2008: 15).

Efectivamente, el concepto de exclusión social no ha desarrollado la capacidad de activación del campo de la denuncia y sí, en cambio, del campo del sentimiento. Y no parece haber sido capaz de alejar, en los modelos de Estados de Derecho apoyados en los principios del Estado de Bienestar, la vieja canción: definir un sistema para gestionar un universo de escoria social, física y moral.

En la práctica, lo que abordamos desde los sistemas de servicios sociales cuando hablamos de exclusión social es una respuesta reactiva orientada a situaciones de pobreza, de excepcionalidad social sin recursos de autogestión, desde un abordaje paliativo (Uribe, 2019: 82). Como apunta Aguilar Hendrickson, Sin capacidad correcta de respuesta a situaciones generalizadas, y entendidos "no tanto como un pilar del Estado Social, sino como un último nivel” (Aguilar Hendrickson, 2014: 19).

\section{4. ¿Cuál es, pues, el espacio natural de los servicios sociales?}

Ciertamente, los servicios sociales han heredado el sistema de gestión y control de la escoria, hoy "exclusión social", un sistema superviviente al paso de los siglos al que se ha dado continuidad. Sistema actualizado, inmensamente mejorado, dignificado, reflexionado y al que se ha dedicado una ingente creación de conocimiento que mejora de forma incuestionable con relación a pasados siglos tanto la operativa como la orientación y los resultados. Pero es, en gran medida, el mismo sistema mejorado. Además, el propio sistema no ha podido -ni por sí mismo, ni ha contado con los apoyos necesariosgenerar un conocimiento suficiente como para romper con el sistema heredado y articular lo que realmente la sociedad necesita de un sistema de servicios sociales.

Por otro lado, estos se han construido a partir del sistema de seguridad social, pero: ¿de verdad creemos que "es su misión revertir la situación de las víctimas del orden social y económico"? (Martínez Veiga, 2008: 14, citando a Donzelot) ¿0 esa es la misión del conjunto de los pilares y sistemas de los Estados de Derecho? Como ejemplo, la Comisión Europea informaba en su informe de seguimiento del primer semestre de 2019 abordando la inclusión social de forma univoca y exclusiva en tanto que una cuestión de mercado laboral, educación y formación -aspectos relativos todos a los sistemas de empleo y educativo-, citando a su vez un informe del Grupo de Trabajo GT2 sobre Transiciones entre Ingresos Mínimos y Empleo. Informe de Resultados (2018), que enfoca al sistema de servicios sociales como un mero auxiliar al servicio del proceso de incorporación al mercado laboral de las personas excluidas del mismo.
Así pues, en el siglo XXI, ¿alguna de estas tres perspectivas, es decir, dar continuidad al sistema histórico de gestión de la escoria, revertir por sí solos el fracaso del resto de sistemas del Estado de Derecho en determinados segmentos de la sociedad, o dar respuesta al "campo del sentimiento" ha de ser el encargo de los sistemas de servicios sociales? La respuesta es: no. Su misión no es la de despolitizar a los sujetos por los que trabaja. Ni controlarlos, en una combinación de métodos actuales con métodos seculares. Ni tampoco lo es revertir los vacíos y fracasos que corresponden competencialmente al resto de sistemas del conjunto de un Estado (ocupación, ingresos suficientes, educación, formación, salud, vivienda, etc.). ¿Cuál es, pues, el rol que deben ocupar los servicios sociales, como uno de los pilares del Estado de Bienestar?

\section{Interacción y agencia}

Hoy en día, los debates sobre el qué y el cómo de los servicios sociales, hablan, entre otros temas, de complejidad, de autonomía, de modelo centrado en la persona. La complejidad es un factor emergente de dificultad añadida a la atención a las personas. Implica una abundancia de casos que tienden a incrementar día a día, que llegan a la necesidad de apoyo de los servicios sociales por múltiples factores y desde múltiples ámbitos de la esfera de la persona (salud, económicos, afectivos, legales, habitacionales, etc.) y en distintos niveles de intensidad. Si bien la complejidad como tal es todavía un territorio bastante inexplorado a nivel de investigación desde las ciencias sociales aplicadas, nadie parece cuestionar su importancia estratégica de presente y futuro, así como la contundencia con la que ataca la línea de flotación de los sistemas, servicios, dispositivos y circuitos sociales actuales: fijos, estáticos, complicados y centrados en sí mismos. La complejidad nos obliga a atender a la persona y a construir respuestas a medida de su situación.

La autonomía es también uno de los objetivos teóricos de la mayoría de las intervenciones sociales, al menos en el discurso. Este se construye a partir de una combinación de reconocimiento del derecho de la persona atendida a decidir y mantener su libertad, así como de la evolución hacia una concepción ecológica de la intervención social que entiende que cada persona es más capaz de ser ella misma en su propio contexto, entorno y comunidad.

El modelo centrado en la persona, también poco investigado en ciencias sociales - al menos en relación con las ciencias de la salud-, nos habla de ese respeto hacia la persona y sus derechos, con la visión puesta en darle un giro radical a la hasta ahora necesidad de que la persona se oriente al sistema, para pasar a hacer pivotar a este en función de cada persona. Una organización que pueda responder a las necesidades de la complejidad y respetar la autonomía. Dawn Brooker, una de las 
referentes en este modelo de atención, plantea como una de sus ideas centrales el desarrollo de un entorno social positivo en el que la persona pueda desarrollar el mejor bienestar posible (Brooker y Latham, 2006). Al respecto, un profesional de servicios sociales preguntaba en una red social: "Y si lo trasladásemos al campo social, ¿serviría?”. Ante lo que nos podemos preguntar a su vez: ¿No sería esta, de hecho, la misión fundamental de los servicios sociales? En cualquier caso, los servicios sociales son otra cosa. Básicamente, la que hemos descrito anteriormente: la perpetuación en la materialización de un sistema de pensamiento antiguo basado en el control y gestión de la escoria social, que asume como puede el encargo de triunfar en los espacios en los que otros sistemas diferentes y de alta especialización han fracasado, y que con frecuencia hace pivotar su acción desde el ámbito del sentimiento.

Más allá del enfoque centrado en la persona y de la atención a la complejidad, otro aspecto del momento actual del debate sobre lo que deberíamos entender como misión de los servicios sociales se explica por sí solo con ejemplos como estos recogidos en redes sociales. Una persona manifiesta ${ }^{2}$ que: "las personas acudimos los servicios sociales porque tenemos problemas en lo relacional, de dependencia o dificultades materiales, y una nivel de densidad de cosas que no suelen venir al caso de nuestro sistema...”, a lo que sigue un interesante hilo, en el que otra persona se pregunta: "Para mí está claro hacia dónde hay que ir. La pregunta también es si la persona quiere explorar o va a los servicios sociales como si fueran una máquina expendedora de tramitación y recursos. ¿Cómo ve el trabajo social la ciudadanía?”. Una tercera interviene: “Pues depende. Con necesidades básicas cubiertas perciben al trabajador social como lo que somos y deberíamos ser: un soporte para acompañarle en la multitud de dificultades q no le permiten avanzar y poco tienen que ver con lo económico".

Otro ejemplo: en diciembre de 2019, otro mensaje en redes sociales decía que "La exclusión social cuando se mantiene en el tiempo genera fracturas personales, familiares y sociales que requieren de generaciones para ser superadas. En Madrid URGE una política de inclusión social focalizada e integral orientada a las personas condenadas a la pobreza severa"3.

Es incuestionable que la precarización en relación con la sociedad salarial, sumada al debilitamiento de red social, conduce a las personas a su anulación de la sociedad de referencia. Esta anulación podrá ser autofacilitada por la dificultad de las personas en gestionar su situación, o podrá también ser

${ }^{2}$ https://twitter.com/Demies36/

status $/ 1223904022089949184$ ? $s=09$ (consultado el 7 de febrero de 2020).

3 https://twitter.com/Luisnogues5/

status/1211248313288269824?s=09 (consultado el 13 de febrero de 2020). generada o acompañada por un entorno, formal o informal, que progresivamente deja de considerarlas como sujetos de derecho (social, legal) del grupo. Pero eso nos lleva a entender que los elementos de exclusión de la sociedad salarial (macroestructuras económica y legal; adecuación de los sistemas de empleo, salud, formación y habitación a las necesidades del conjunto completo de la sociedad), así como los factores de contexto que debilitan los lazos de las personas (de salud, de acceso al empleo $u$ otros ingresos, de reconocimiento de derechos), corresponden a los sistemas respectivos del Estado de Derecho (sistemas sanitario, formativo, de empleabilidad, relativo a la vivienda y al marco legal). Y que los elementos relativos al debilitamiento de la red social, así como a la restitución de la situación previa a la anulación del individuo como parte activa y de derecho de su sociedad de referencia corresponde, esa sí, pero específicamente esa, a los servicios sociales en tanto que sistema especializado. Y, atención, “solamente" en este aspecto: el de la activación de recursos, técnicas y métodos de apoyo a la persona en el seno de su comunidad de referencia, con el objeto de mantener a estas activas y plenas en sus capacidades y posibilidades de ejercicio de la libertad.

Es posiblemente desde esta doble perspectiva que la Organización Mundial de la Salud (OMS) define la exclusión social con relación a la vivencia de situaciones de pobreza, así como de marginación, como resultado del racismo, la discriminación, la estigmatización, la hostilidad y el desempleo (Wilkinson y Marmot, 2003: 16) y a su vez aborda lo que define como apoyo social, afirmando que: "El apoyo social proporciona a las personas los recursos emocionales y prácticos que necesitan. Pertenecer a una red de apoyo basada en la comunicación y en el establecimiento de obligaciones mutuas hace que la gente se sienta cuidada, querida, estimada y valorada. Y todo ello ejerce un poderoso efecto protector sobre la salud”. Además, “la cohesión social -definida como la calidad de relaciones sociales y la existencia de confianza, obligaciones mutuas y respeto en la comunidad o en la sociedad más extensa- ayuda a proteger a las personas y a su salud" (Wilkinson y Marmot, 2003: 22).

Es decir, de un lado, los vectores relativos a los puntos de crisis o fractura en la sociedad salarial y redes sociales y, de otro, la comunidad en tanto que fundamento orgánico de lo social como proveedora de activos restauradores de la persona y, por extensión, de la comunidad.

También Naciones Unidas afirma en su informe Leaving no one behind: the imperative of inclusive development ${ }^{4}$, que la exclusión social es un: “[...] estado en el que las personas no son capaces de participar de forma plena en la vida económica, social, política y cultural, así como el proceso que la lleva y/o mantiene en esta situación” (Naciones

${ }^{4}$ https://www.un.org/esa/socdev/rwss/2016/full-report.pdf. 
Unidas, 2016: 18). A su vez, define inclusión social como: "el proceso de mejora de los termino de participación en la Sociedad por parte de personas que están en situación de desventaja por razón de edad, sexo, discapacidad, raza, etnia, origen, religión, o estatus económico, mediante oportunidades entrelazadas, acceso a recursos, voz y respeto hacia sus derechos" (Naciones Unidas, 2016: 20).

Ambos organismos internacionales identifican, pues, la incapacidad de formar parte de la sociedad con plenitud como el elemento crítico que conduce a lo que llamamos exclusión social, así como el objeto a restaurar - la inclusión social-, y que sería, de hecho, el espacio específico de los servicios sociales.

No debemos perder de vista que, como apunta Daniel Innerarity (2019), deberíamos superar las formas de organización propias de los siglos XIX y XX desde las que los individuos debemos disciplinarnos y negociar nuestro espacio en la sociedad a partir de un modelo basado en la física, y desde la negociación personal en un entramado de equilibrios entre fuerzas y pesos (por ejemplo, entre administración municipal y supramunicipal; entre sistemas de servicios sociales y otros sistemas; entre marcos legales, etc.). En pleno siglo XXI, deberíamos avanzar hacia un nuevo formato biológico de comprensión y gestión de las sociedades a nivel político, legal, social, de modelo, en el que la célula (entendida como el individuo, la persona), dispone de un ADN único que modeliza y tiene por ende la capacidad de alterar el conjunto de su sistema desde su unicidad.

¿Cómo materializar, pues, la transición entre el modelo clásico de servicios sociales y el que definen progresivamente tanto los discursos teóricos como el propio sentir inspirado en la experiencia cotidiana? Una transición que, dicho sea de paso, sería razonable comenzar antes de llegar al colapso de las sociedades que, por un sumatorio de incremento de la desigualdad sumado al incremento de la complejidad, combinado a su vez con el fracaso en el abordaje de estos problemas por parte de los sistemas de salud, empleo, formación, económico, legal, terminará por fulminar lo que son hoy nuestros sistemas de servicios sociales, y poner en crisis sistémica a nuestras sociedades.

Lo que unos u otros parecen definir con relación al papel central de la participación en la sociedad de toda persona como uno de los ejes más importantes, a la vez que complejos y específicos de la posibilidad de supervivencia, es lo que introduce de manera certera y clara Fernando Fantova con su definición y propuesta de desarrollo del concepto de “interacción”. Para este autor, la interacción sería "el ajuste entre la capacidad de desenvolvimiento autónomo de la persona en sus entornos vitales y el apoyo social disponible a través de los vínculos familiares, convivenciales, comunitarios y sociales en general" (Fantova, 2007: 191), lo cual nos lleva a entender la intervención social como "la actividad que tiene como finalidad prevenir, corregir o paliar desajustes en lo relativo a la interacción de las personas, con sus dos caras o dimensiones: autonomía funcional e integración relación" (Fantova, 2017: 13).

Desde esta definición de interacción, Fantova acota una nueva visión de la misión de los servicios sociales totalmente en línea con las aproximaciones que recientemente se vienen realizando desde la identificación de situaciones de complejidad, de atención centrada en la persona, y reconociendo cuál es el espacio propio, especializado y concreto de los servicios sociales que, por otra parte, evidencia la no pertinencia de aquellos que clásicamente aborda, por herencia o por delegación formal o informal. De hecho, la propuesta de Fantova supone un esperado encuentro con ciencias sociales como la sociología o la antropología, que sitúan la interacción (personal, social), como uno de los ejes fundamentales del hecho social.

El espacio físico que ocupamos tiene significado en tanto que en él (nos) ocurran cosas o cuanto menos, las proyectemos. Delgado toma de Simmel que: "el espacio no es sino la posibilidad de juntar” $y$, citando a Julio Cortázar, afirma que: "un puente es un hombre cruzando un puente” (Delgado, 2016). Reconocemos el espacio que ocupamos en tanto que lo experimentamos, es decir, interactuamos con él y en él, el hecho social se construye de interacción. Y con una insuficiente, deficiente o lesiva interacción, los individuos vemos reducidas nuestras posibilidades de ser -en tanto que somos lo que hacemos-, al no tener qué hacer en relación a los otros -que acompañan, limitan o posibilitan- nuestro yo.

Durkheim definió los hechos sociales como los modos de pensar, sentir y accionar de manera exterior al individuo, en forma de orientación y coerción sobre cómo debe comportarse este. Para Georg Simmel, la sociedad se constituye a través de las interacciones entre individuos y grupos, en constante ebullición, en permanente construcción y reconstrucción a partir de la suma de microencuentros. La sociedad es interacción. No puede haber sociedad sin ella. Y, por tanto, sin una suficiente interacción, los individuos no pueden formar parte de la sociedad, o hacerlo libremente. Entendida - la sociedad- no desde lo abstracto, sino desde lo que es: la experiencia de lo cotidiano, y en igualdad de condiciones con los iguales.

No es casual que otro de los autores referentes desde la sociología en relación con lo que se conoce como exclusión social sea Erving Goffman, autor de obras como: Relaciones en público. Microestudios del orden público; Ritual de la interacción; Internados. Ensayos sobre la situación social de los enfermos mentales; Estigma. La identidad deteriorada, por citar algunas, y que se encuadra en la línea de las microsociologías (Joseph, 1999) siendo también referente del interaccionismo simbólico que Blumer (1982) nos presenta a partir de entender que el significado de 
una conducta se forma en la interacción social. Lo que Goffman aportó en la comprensión de diversas categorías vinculadas a exclusión social y su abordaje en línea con la consideración de escoria social, se fundamenta en estudios que exploran las limitaciones y posibilidades de ejercicio de la interacción en libertad.

Somos lo que hacemos. Y, por tanto, socialmente somos aquello que en el orden de las interacciones tenemos la capacidad de hacer, pactar, negociar, conseguir en nuestras interacciones con otros. Si tenemos seriamente mermada la capacidad de interactuar, somos individuos en riesgo de no poder ser quienes somos - al no poder hacer lo que queremos hacer-. En otras palabras: es evidente que la interacción social es un elemento crítico en la existencia de situaciones de pobreza y de lo que se da en llamar exclusión social. Y que la primera es generadora de la segunda y tercera tanto como, 0 más, que la segunda y tercera puedan llevar también a la primera.

En el fondo, y desde esta perspectiva, a donde nos lleva Fantova con su propuesta de interacción y esta como misión de los servicios sociales, es a hablar de la capacidad de ser libres - no solo personas autónomas, también libres-, y de cómo no poder interactuar restringe significativamente o acaba con nuestra libertad. La misión de los servicios sociales, es, pues, retomando las anteriores citas de Fantova, la de restituir y mantener la libertad de las personas desde su capacidad de sostener la interacción. Armonizando, equilibrando en aquellas personas que necesiten apoyo especializado su capacidad de desenvolvimiento autónomo en sus entornos vitales, con el apoyo social disponible a través de los vínculos posibles, a nivel familiar, convivencial, comunitario y social (Fantova, 2007:191): autonomía personal más integración, y relación (Fantova: 2017:13). La capacidad individual para sostener una posición entre el grupo social se convierte así en tema central, muy en línea de los trabajos que aportan Amartya Sen y Martha Nussbaum a través del enfoque basado en las capacidades -teoría económica del primero-, y posteriores desarrollos conjuntos de ambos, orientados a sistematizar el rol de las capacidades como elemento clave alrededor de las cuales organizar sistemas de apoyo, cuando sea necesario, en tanto que estas serían claves en las opciones de libertad real de la persona. Sin las capacidades suficientes o adecuadas, la interacción con el grupo de iguales no es posible o no es igualitaria y la persona decae en su posibilidad de ser quien quiera ser y hacer lo que quiera hacer.

Todo ello nos lleva también a Begoña Román, cuando afirma que las entidades sociales - en tanto que servicios sociales-, deberían tomar como objetivo central "ayudar a las comunidades a crear agencia [...] si has transformado y has creado agencia, para que estas comunidades puedan nacer sin tu ayuda, entonces la acción social es prescindible” (Román, 2019). De hecho, esta autora afirma que: “los principales objetivos de los servicios sociales son la justicia social, la integración y la cohesión social” (Román, 2016: 13). Para cumplir con ello, los servicios sociales deben situarse dentro de la lógica del apoyo a la restauración y mantenimiento de la capacidad de interacción en los términos definidos, para acompañar la creación de agencia suficiente (justicia social), que sentará las bases desde la misión del sistema de servicios sociales para lo que se da en llamar integración (participación en términos de equidad de todos sus miembros) y, por tanto, favorecer la cohesión social desde la perspectiva de las lógicas del devenir social en tanto que todos sus miembros tendrán a su alcance opciones igualitarias para conseguir sus objetivos en sociedad o, cuanto menos, para pactarlas y pactar también sus renuncias a ellas en términos de justicia.

El encaje del individuo en la sociedad sería, pues, el espacio de los servicios sociales. Sin dirigismos, sin moralismos: acompañar desde el conocimiento especializado la restitución de la agencia de la persona mediante la restitución, y el mantenimiento, de su capacidad de interacción. Y mientras estos servicios no se orientan de manera masiva hacia este objetivo, la soledad y el aislamiento social tienen un cada vez más elevado peso porcentual ${ }^{5}$-ya altísimo- en personas que verán sin duda empeorar sus condiciones de vida si ambas no son revertidas por la generación de agencia.

\section{Libertad y retos: conclusión}

Quizá lo que llamamos exclusión social no es más que la perpetuación del estigma, la construcción y mantenimiento de un gólem materializado por la sociedad y su sistema, una generación tras otra. Incluso por el sistema de servicios sociales que, heredero de una tradición y una inercia, ha encarnado el abordaje en positivo a veces, otras no, de un estigma y su peso... El pecado original ha sido construir un sistema concebido para dar respuesta a la gestión de un estigma.

El momento actual, de madurez y de cierta capacidad de investigación, debate y reflexión sobre qué deben ser y cómo deben articularse los servicios sociales, nos ha llevado a, primero, una gran evolución en los últimos cuarenta años en la capacidad de generar respuestas eficientes y conformes con los derechos de las personas - a pesar de las tensiones que este sistema genera a personas destinatarias de los servicios, así como a profesionales-. Y, segundo, a un presente en el que una mayoría de personas (profesionales y ciudadanía en general), entiende que la misión en la que los servicios sociales deberían ser monográficamente competentes es la del apoyo de las personas que lo necesiten al mantenimiento en su contexto social.

5 https://observatoriosociallacaixa.org/es/-/soledad-personasmayores (consultado el 14 de febrero de 2020). 
Fantova activa, a partir del concepto de interacción desde el apoyo en la restitución y mejora de la autonomía funcional y de la integración relación, un terreno nítido, a la vez acotado, y también facilitador de la identificación de los límites - hoy inexistentes o claramente rebasados-, entre lo que compete a los sistemas de servicios sociales y lo que compete al resto de sistemas fundamentales del Estado de Derecho, ayudándonos a centrar que un problema de salud es un problema de salud. Un problema de vivienda, lo es de vivienda. Un problema de empleo, lo es de empleo; uno de restricción de derechos por contexto legal, es un problema de marco legal, y así sucesivamente, para todo lo cual, afortunadamente, existen en el Estado de Derecho sistemas articulados, altamente especializados y competentes.

Los grandes retos podrían centrarse en los límites y en los cambios. Límites: definir -de forma correcta y no tendente, como es norma hasta el momento, a declinar de manera automática en los sistemas de servicios sociales cuando desde algún sistema paralelo se identifica una situación específica de "exclusión social" dentro de los márgenes de su espacio natural de competencia- hasta dónde deben llegar los contenidos de la intervención de los servicios sociales en el apoyo a los sistemas paralelos, sin dejar de centrar su acción monográfica en la restitución de la interacción. Cambios: el nuevo enfoque supone una refundación de los servicios sociales. Algo imposible sin el pacto de Estado y social necesario, con la consiguiente inversión y planificación. Pero, atención, no olvidemos que la misión de los servicios sociales es la de apoyar el mantenimiento y ejercicio de la libertad de las personas. Que su objetivo, nos dice Román, es el de la justicia social, la integración y la cohesión social que aquí hemos tratado de objetivar para entender hasta qué punto son centrales para la supervivencia de cualquier sociedad. Así que el coste, sea el que sea, ha de ser asumible.

Por un lado, los otros sistemas del Estado de Derecho deberían asumir - con los recursos necesarios- la convulsión que implicaría asumir como principales agentes responsables de gestión una gran parte de lo que actualmente asumen los servicios sociales en España. A su vez, los servicios sociales deberían poderse dotar de profesionales y servicios adecuados en aquellos ámbitos que, situados en ese límite entre el sistema propio y los otros, deba atender. Un ejemplo está en la cada vez más clara, pero aún difícil de concretar por falta de recursos, necesidad de especializar los actuales servicios de prestaciones sociales con personal administrativo y canales facilitadores para la ciudadanía sin comprometer servicios, circuitos y profesionales especializados en el acompañamiento social. Y, así, sucesivamente. Pero también, y básicamente, debería producirse una redefinición de arriba abajo: del marco legal genérico que define las competencias de los servicios sociales, los reglamentos que lo desarrollan, la definición posterior de las carteras de servicios sociales, libros blancos de las profesiones sociales, los circuitos, los protocolos, etc.
Otra cuestión es la de la incorporación real del trabajo comunitario. El Estado español tiene mucho que andar todavía en el desarrollo de este ámbito como un campo de acompañamiento social, muy limitado hoy en día a intentar poner en contacto a personas solas con espacios en los que hay más gente, como bibliotecas o centros públicos. El trabajo comunitario va mucho más allá de eso: implica la activación de la comunidad, desde técnicas y procesos especializados a través de la puesta en contacto efectiva de la persona acompañada con la comunidad y de esta con la persona, generando un nivel y calidad de interacción que propicie la agencia hasta que la persona no necesite de más acompañamiento social. Esta visión, además, debe ser rápidamente incorporada a los servicios sociales de secundaria o especializados, los cuales adolecen de una gran influencia de modelos del pasado en su diseño actual y, por lo tanto, tienden a favorecer -sin que sea intención ni de gestores del sistema ni de profesionales de acompañamiento- a la desconexión respecto de la comunidad de gran parte de las personas a las que atienden: tanto o más como los básicos o de primaria, los servicios sociales de secundaria o especializados precisan con urgencia un rediseño en el que el trabajo comunitario tenga un papel central que redundará además en una mejor respuesta a la complejidad y desde la lógica del modelo de atención centrado en la persona.

Por otra parte, es conocida la influencia del espacio y el tiempo en el acompañamiento social: ciertos espacios propuestos a las personas son altamente efectivos; en cambio, otros son críticamente inadecuados. También sabemos que el tiempo de acompañamiento es una de las fuentes de problemas cuando el disponible por marco legal o disponibilidad de recursos es insuficiente respecto a la que necesita ese proceso personal. Claramente, otros factores son también de gran importancia, pero este ejemplo nos sirve para introducir un nuevo factor que guardaría una relación directa con la posibilidad de activación del trabajo comunitario: el territorio, que podemos entender como la porción de espacio propio de un grupo o comunidad en el que desarrollar - pactar, definir, negociar, conflictuar- la relación social. Esta variable debería ser introducida con urgencia en la intervención social, como lo están ya el espacio y el tiempo, como uno de los elementos cuya mala gestión puede propiciar fracaso o éxito en un acompañamiento centrado en apoyar la interacción de las personas con su grupo (o alguno de sus grupos) de referencia. Como ejemplo, el desarrollo en la ciudad de Barcelona de las superilles socials ${ }^{6}$ (supermanzanas sociales), en desarrollo a partir de un modelo en ejecución ya consolidado en Holanda y que tiene como objetivo apoyar el mantenimiento de personas con determinadas necesidades sociales en su propio contexto -en lugar de tender a su institucionalización-, potenciando su posibilidad

6 https://ajuntament.barcelona.cat/dretssocials/ca/innovaciosocial/superilles-socials (consultado el 14/02/2020). 
de agencia a través del apoyo en la generación de interacción, reforzando las capacidades propias y enlazándolas con las posibilidades y necesidades de la comunidad de referencia. También las técnicas de acompañamiento y la posición del personal profesional respecto a las personas acompañadas deberán complementarse en algunos aspectos, con metodologías aún poco exploradas, y modificarse en otros, muy basados en las clásicas relaciones de poder de la relación entre profesional y "excluido/a social”. Finalmente, hay que cambiar la mirada. De manera radical. No como una declaración de intenciones, sino como herramienta básica de gestión del cambio: como ya se ha apuntado aquí, esta visión de cuál es la auténtica misión de los servicios sociales, si bien es conocida y compartida desde la gestión del día a día, apenas ha sido formalizada precisamente porque, a pesar de que la experiencia nos lleva a entender la necesidad de abordaje distinto, la lógica no ha cambiado y el discurso, precursor del análisis profundo y de toma de decisiones, no se ha originado. Solo desde una apertura a una mirada distinta de lo que son, y de lo que deben ser, los servicios sociales, podremos sumar las fuerzas necesarias desde todos los estamentos implicados para operar el cambio de los sistemas de servicios sociales. Por la libertad, acabemos, pues, con la prisión de los conceptos. 


\section{Bibliografía referenciada}

AGUILAR HENDRICKSON, M. (2014): “Apuntes para un replanteamiento de los servicios sociales en España", VII Informe sobre exclusión y desarrollo social en España 2014, Madrid, Fundación Foessa.

BAUDELAIRE, C. (1996): Las flores del mal, Madrid, Visor Libros.

BEVERIDGE, W.H. (1987): "Mantenimiento de la ocupación", en BEVERIDGE, W.H., Las bases de la seguridad social, México, Fondo de Cultura Económica, pp. 51-52.

BLUMER, H. (1982): El interaccionismo simbólico: perspectiva y método, Barcelona, Hora.

BROOKER, D. y LATHAM, I. (2006): Person-centred Dementia Care: Making Services Better, Londres, Jessica Kingsley Publishers.

DELGADO, M. (2016): “Un puente es un hombre cruzando un puente", El Cor de les Aparences [blog], 6 de septiembre <http://manueldelgadoruiz. blogspot.com/2016/09/un-puente-es-unhombre-cruzando-un.htmls.

DICKENS, C. (2015): Oliver Twist, Madrid, Alianza.

- (2019): Cuentos de Navidad, Madrid, Alianza.

DURKHEIM, E. (2001): Las reglas del método sociológico, México D.F., Fondo de Cultura Económica.

DONZELOT, J. y ROMAN, J. (1991): “La deplacement de la question sociale”, en DONZELOT, J. (ed.), Face à l'exclusion: le modèle français, París, Esprit.

ENGELS, F. (2008): Del socialismo utópico al socialismo científico, Barcelona, Debarris.

FANTOVA, F. (2007): “Repensando la intervención social”, Documentación Social, no 147, pp. 183-198.

- (2017): "Servicios sociales e inclusión social: análisis y perspectivas en el País Vasco", Zerbitzuan, nำ
64, pp. 9-31, 〈https://doi.org/10.5569/11347147.64.01>.

GOFFMAN, E. (1970): Ritual de la interacción, Buenos Aires, Tiempo Contemporáneo.

(1979): Relaciones en público. Microestudios del orden público, Madrid, Alianza.

(1984): Internados. Ensayos sobre la situación social de los enfermos mentales, Buenos Aires, Amorrortu.

(1987): La presentación de la persona en la vida cotidiana, Buenos Aires, Amorrortu.

(1995): Estigma. La identidad deteriorada, Buenos Aires, Amorrortu.

GRUPO DE TRABAJO GT2 SOBRE TRANSICIONES ENTRE INGRESOS MÍNIMOS Y EMPLEO (2018): Informe de resultados. Reunión presencial 27.06.2018. Versión final, Red de Inclusión Social, «http://redinclusionsocial.es/wpcontent/uploads/2018/10/INFORME-GT2.2TRANSICIONES-FINAL-2.pdf〉.

INNERARITY, D. (2019): Una teoría de la democracia compleja, Barcelona, Galaxia Gutenberg.

JOSEPH, I. (1999): Erving Goffman y la microsociologia, Barcelona, Gedisa.

LENOIR, R. (1974): Les Exclus, un Français sur dix, París, Senil.

LIS-HUGO, C. (1982): Pobreza y capitalismo en la Europa preindustrial (1350-1850), Madrid, Akal.

MARTÍNEZ VEIGA, U. (2008): “Genealogía del concepto de exclusión social, la situación europea”, Trabajo Social Hoy, no extra, pp. 7-43.

MARX, C. y ENGELS, F. (2015): Manifiesto comunista, Madrid, Alianza. 
MONEREO, J.L. (2015): “William Henry Beveridge (18791963): la construcción de los modernos sistemas de seguridad social", en Revista de Derecho de la Seguridad Social, $\mathrm{n}-4$, pp. 279-305, «https://revista.laborum. es/index.php/revsegsoc/article/ view $/ 62 / 63$ ?acceptCookies=1>.

NACIONES UNIDAS (2016): Leaving No One Behind: The Imperative of Inclusive Development. Report on the World Social Situation 2016, Departament of Economic and Social Affairs, ST/ESA/362, Nueva York, Naciones Unidas, 〈https://www. un.org/esa/socdev/rwss/2016/full-report.pdf〉.

ORWELL, G. (2010): Vagabundo en París y Londres, Palencia, Menoscuarto Ediciones.

OWEN, R. (2007): Nueva visión del mundo, Barcelona, Hacer.

PAMPLONA, O.H.(1982): La pobreza y el paro en la ciencia económica [trabajo final de licenciatura], Barcelona, Universitat de Barcelona.

ROMÁN, B. (2016): Ética de los servicios sociales, Barcelona, Herder.

- (2019): “El nostre món ha esgotat les possibilitats de canvi. Ens toca canviar les institucions" [entrevista de Cristina Garde y Mar Barberà], Social.cat, 11 de octubre, en https://www. social.cat/entrevista/10899/el-nostre-monha-esgotat-les-possibilitats-de-canvi-ens-tocacanviar-les-institucions?id_butlleti_enviar=8>.

SCHUMPETER, J. A. (1982): Historia del análisis económico, Barcelona, Ariel.

SIMMEL, G. (1977): Sociología. Estudios sobre las formas de socialización, 2 vols., Madrid, Revista de Occidente.

URIBE, J. (2019): “Rellenando espacios: hacia una ordenación de los sistemas de servicios sociales desde la respuesta a la complejidad", Zerbitzuan, no 68, pp. 75-90, 〈https://doi. org/10.5569/1134-7147.68.06>.

VILÀ, A. (2004): "Els serveis socials a Catalunya. Una visió histórica" [tesis doctoral], Girona, Universitat de Girona, 〈https://www.tdx. cat/bitstream/handle/10803/7966/tavm. pdf? sequence $=7$ \&isAllowed $=\mathrm{y}$ >.

WOOLF, S. (1989): Los pobres en la Europa Moderna, Barcelona, Crítica.

WOOLF, V. (1976): Fin de viaje, Barcelona, Luis de Caralt.

WILKINSON, R. y MARMOT, M. (eds.) (2003): Los hechos probados. Los determinantes sociales de la salud, Organización Mundial de la Salud, Ministerio de Sanidad y Consumo. 